\title{
A New Process for Soy Sauce Fermentation by Immobilized Yeasts
}

\author{
Hiroyuki Horitsu, Yuto Maseda and Keiichi Kawai \\ Department of Bioresources Utilization, Faculty of Agriculture, \\ Gifu University, Yanagido 1-1, Gifu 501-11, Japan
}

Received June 26, 1989

\begin{abstract}
Using bioreactors with yeasts, Zygosaccharomyces rouxii that undergoes ethanol fermentation and produces 2-phenyl ethanol, and Candida versatilis that produces 4-ethyl guaiacol, adsorbedimmobilized on a ceramic carrier, the total time required for production of soy sauce was shortened to 8 days without affecting the product's quality.
\end{abstract}

Recently, in addition to conventional techniques, the use of bioreactors with immobilized enzymes and/or immobilized microorganisms in food industry has been popular. A new process using bioreactors with immobilized cells which was different from the conventional soy sauce fermentation was investigated. Osaki et al. ${ }^{1)}$ reported that the use of bioreactors packed with calcium alginateentrapped yeasts shortened the aging of soy sauce fermentation.

Although there would not be any safety problems when calcium alginate gel is used in the food industry, calcium alginate gel is unstable to heat, and therefore can not be sterilized completely by steam. Furthermore, owing to its gel conformation, calcium alginate gel is weak and can be easily damaged by high salt concentrations. Hence, continuous fermentation for a long period of operation would not be feasible. Besides, it is impossible to recycle because the calcium alginate gel is an organic material and therefore would impose a disposal problem. On the basis of these facts, we decided to develop a carrier for immobilization to replace calcium alginate. A new ceramic carrier was developed to get rid of the defects described above. With the new bioreactor, the aim is also to shorten the fermentation time and at the same time producing a good quality of soy sauce.

\section{Materials and Methods}

Microorganisms. The soy sauce yeasts used in this experiment were Zygosaccharomyces rouxii IFO 1877 as a main producer of ethanol and aromatic components like 2-phenyl ethanol (2-PE), and Candida versatilis G001 in charge with the production of 4-ethyl guaiacol (4-EG).

Culture solution and feed solution for fermentation. Growth medium for soy sauce yeasts consists of $20 \mathrm{~g}$ of glucose, $3 \mathrm{~g}$ of malt extract, $5 \mathrm{~g}$ of Polypeptone, $5 \mathrm{~g}$ of yeast extract,

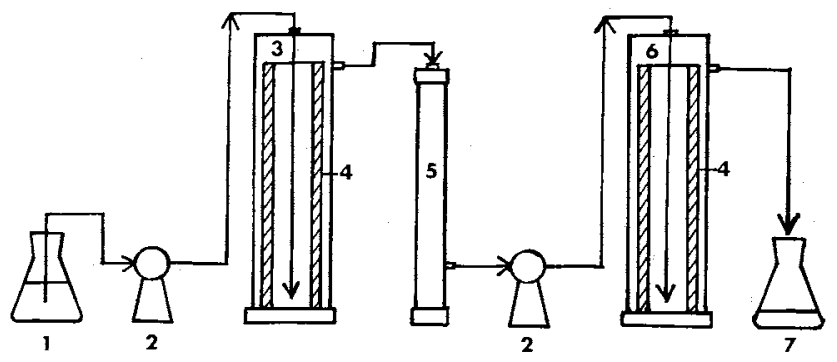

Fig. 1. Schematic Flow Diagram of Reactors for Soy Sauce Production by Immobilized Yeasts with Ceramic Carrier.

(1) feed tank; (2) pump; (3) reactor I; (4) ceramic carrier; (5) ceramic filter; (6) reactor II; (7) reservoir. 
and $60 \mathrm{~g}$ of $\mathrm{NaCl}$, dissolved in $50 \mathrm{ml}$ of raw soy sauce and diluted to 1 liter at $\mathrm{pH} 5.0$ before sterilization. The feed solution used for the bioreactor was prepared by the method of Takamatsu et al. ${ }^{2}$; $10 \%$ saline solution was added to the soy sauce koji, made from steam-boiled soybeans, roasted wheat, and koji microbes, and digested below $55^{\circ} \mathrm{C}$. The digest was fermented with lactic acid bacterium, Pediococcus halophilus for lactic acid fermentation. The cell-free filtrate that was passed through a membrane filter was used as a feed solution for fermentation. The feed solution used in this experiment was kindly supplied by Kikkoman Corporation.

Cultivation of yeasts. Soy sauce yeasts (Zygo. rouxil and C. versatilis) were inoculated separately into $100 \mathrm{ml}$ of growth medium in a $500-\mathrm{ml}$ flask and cultivated aerobically at $30^{\circ} \mathrm{C}$ for $60 \mathrm{hr}(6-\mathrm{cm}$ stroke, and 133 reciprocations $/ \mathrm{min}$ ). This comprised the seed culture. The main culture was placed in a 2-1 jar fermentor containing 1.21 of growth medium and the yeast harvested from the seed culture by centrifugation. Cultivation was done at 500 rpm with stirring aeration at a rate of $51 / \mathrm{min}$ for $24 \mathrm{hr}$ at $30^{\circ} \mathrm{C}$.

Reactors and method of immobilization. The reactors used for fermentation are shown in Fig. 1. These column reactors are made of stainless steel (height, $30 \mathrm{~cm}$; diameter, $10 \mathrm{~cm}$ ), and a working volume of $900 \mathrm{ml}$. The ceramics carrier used for cell immobilization consists of $95 \%$ alumina and $5 \%$ silica, filamentous in structure with an average pore size of $60 \mu \mathrm{m}$ and a porosity of $90 \%$. The carrier forms a column with an outer diameter of $7.5 \mathrm{~cm}$, inner diameter of $5.5 \mathrm{~cm}$ and height of $25 \mathrm{~cm}$. It was a product of Basella Co., Ltd., Japan. Regeneration of used ceramics was done by heating at $900^{\circ} \mathrm{C}$ for $2 \mathrm{hr}$. Bioreactors with the ceramic carrier were sterilized in an autoclave at $120^{\circ} \mathrm{C}$ for $30 \mathrm{~min}$. Zygo. rouxii was adsorbedimmobilized in reactor $I$ and $C$. versatilis in reactor II. A ceramic membrane filter was used to avoid the transfer of free cells from reactor I to reactor II. Both yeasts were harvested by centrifugation, resuspended in 1.31 of feed solution (cell counts, $5 \times 10^{7}$ cells $/ \mathrm{ml}$ ) and placed into separate reactors. Microtube pumps were used to circulate the cell suspension at a flow rate of $20 \mathrm{ml} / \mathrm{min}$ for $12 \mathrm{hr}$. By this treatment, the yeast cells were immobilized on the ceramic carrier.

Analyses. Measurements of sugar, total nitrogen, formol nitrogen total acidity, and $\mathrm{NaCl}$ were done by Hirose's method. ${ }^{3)}$ The concentration of ethanol was measured by Shimadzu gas chromatography GC-4C using a flame ionization detector with chromosorb 101 (60-80 mesh)packed column $(2000 \times 3 \phi \mathrm{mm})$. Aroma components such as ethyl acetate, $n$-propyl alcohols, iso-butyl alcohol, and iso-amyl acetate were analyzed by a Shimadzu head space auto analyzer (GC-9A; HSS-2A). The analyzer column $(2000 \times 3 \phi \mathrm{mm})$ was packed with PEG-20M on chro- mosorb W (AW-DMCS, 60-80 mesh). n-Amyl alcohol and ethyl acetate were used as internal standard solutions. Two characteristic aroma components of soy sauce, 2-PE and 4-EG, were extracted with methyl acetate, and then analyzed by the Shimadzu head space auto analyzer (GC9A; HSS-2A), where 2,3,5-trimethyl phenol was added as a standard solution.

Preparation of sample for scanning electron micrograph. Soy sauce yeast adsorbed on ceramics $(3 \times 5 \times 1 \mathrm{~mm})$ was fixed with glutaraldehyde at $4 \mathrm{C}$ for $1 \mathrm{hr}$, and then immersed in 60,80 , and $100 \%$ acetone for $15 \mathrm{~min}$, each. After substitution with amyl alcohol for $10 \mathrm{~min}$, samples were dried in a Hitachi critical point drying unit HCP-2. Dry samples were then fastened to the sample plate by silver paste and coated with Pt-Pd by vacuum evaporation in a Hitachi E102 ion sputter. Observations were done under a Hitachi H-800 electron microscope at an accelerating voltage of $75 \mathrm{keV}$.

\section{Results and Discussion}

Soy sauce fermentation by free yeasts

Before immobilized yeasts were used for soy sauce fermentation, we mixed up 2 strains of yeasts, Zygo. rouxii and C. versatilis, under normal conditions as a model experiment simulating the conventional fermentation. Feed solution of 1.31 , which contained $2.5 \%$ directreducing sugar and $1 \%$ lactic acid, was placed in 3-1 Erlenmeyer flasks and resuspended with $Z y g o$. rouxii and $C$. versatilis with a total cell count of $5 \times 10^{7}$ cells $/ \mathrm{min}$ in both reactors. Fermentation was done at $30^{\circ} \mathrm{C}$ in stationary culture. The course of this fermentation is presented in Fig. 2. According to this figure, mixed cultivation of the two yeasts readily produced $13 \mathrm{mg} / 1$ of $2-\mathrm{PE}, 1.5 \%$ ethanol, and $20 \mathrm{mg} / \mathrm{l}$ of iso-amyl alcohol on the fourth day of fermentation.

Nevertheless, 4-EG, a unique aroma component in soy sauce could not be detected even after 15 days of cultivation. The reason for this may be due to the unfavorable effect of Zygo. rouxii and $C$. versatilis in mixed culture. From this result, it is necessary to separate these two yeasts and use a ceramic membrane filter between the two bioreactors.

\section{Scanning electron micrographs of immobilized yeasts}

The scanning electron micrographs of soy 

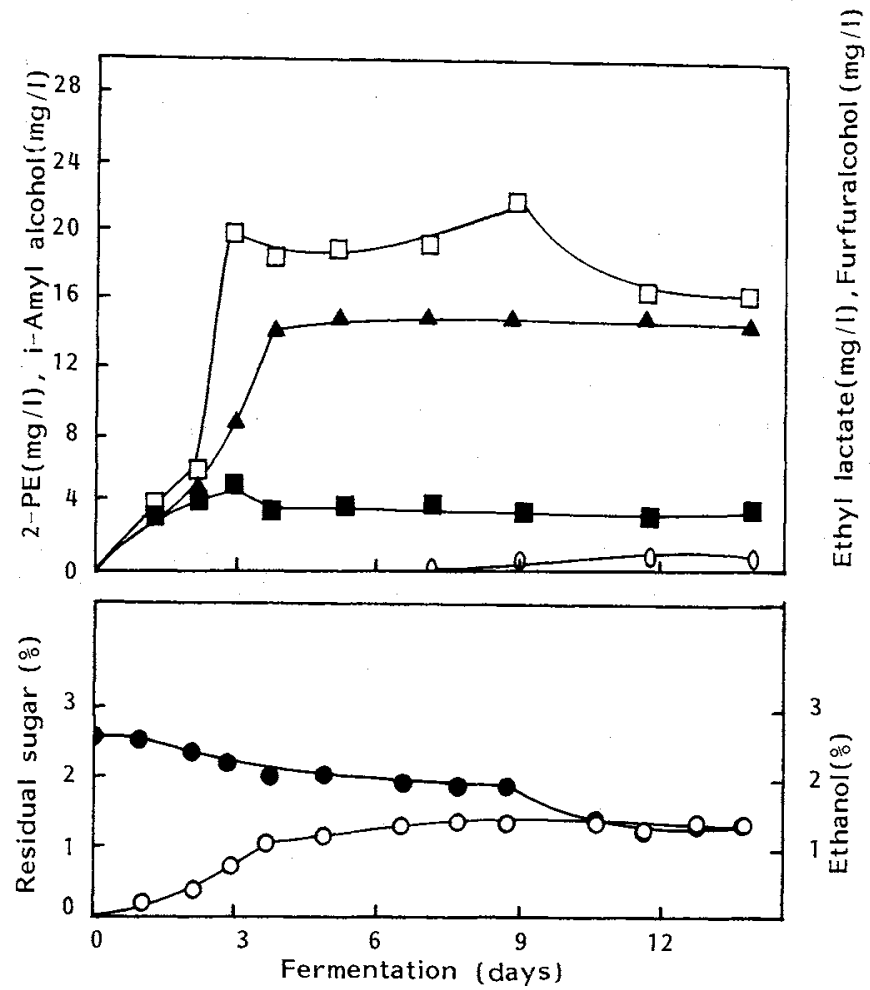

Fig. 2. Course of Residual Sugar, Ethanol, and Aroma Component Production by Mixed Fermentation Using Whole Cells of Zygo. rouxii and C. versatilis.

- residual sugar; $O$, ethanol; $\boldsymbol{\Delta}, 2 \mathrm{PE} ; \square$, iso-amyl alcohol; $\boldsymbol{\square}$, ethyl lactate; $\bigcirc$, furfuralcohol.

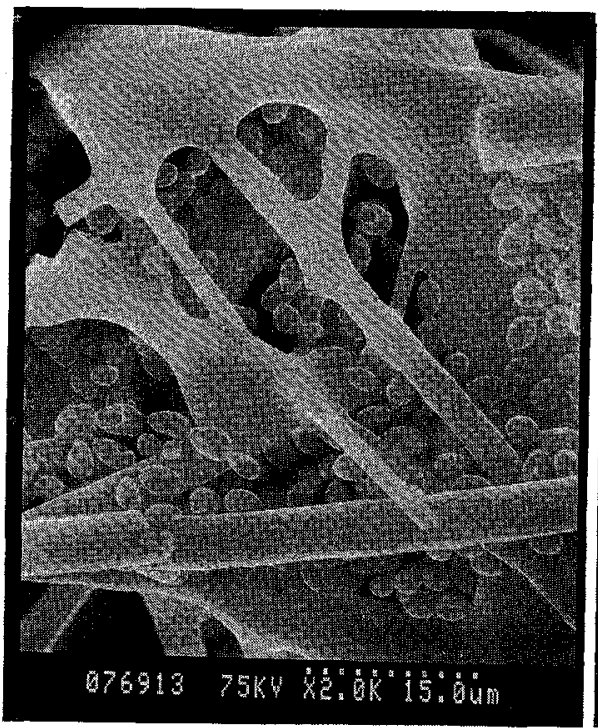

(a)

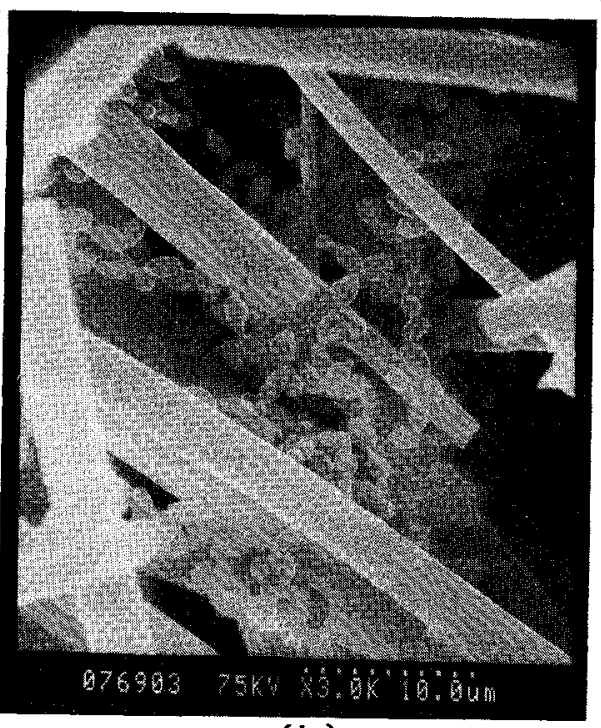

(b)

Fig. 3. Scanning Electron Micrographs of Yeasts Adsorbed on Ceramic Carrier.

(a) Z. rouxii (reactor I); (b) C. versatilis (reactor II). 


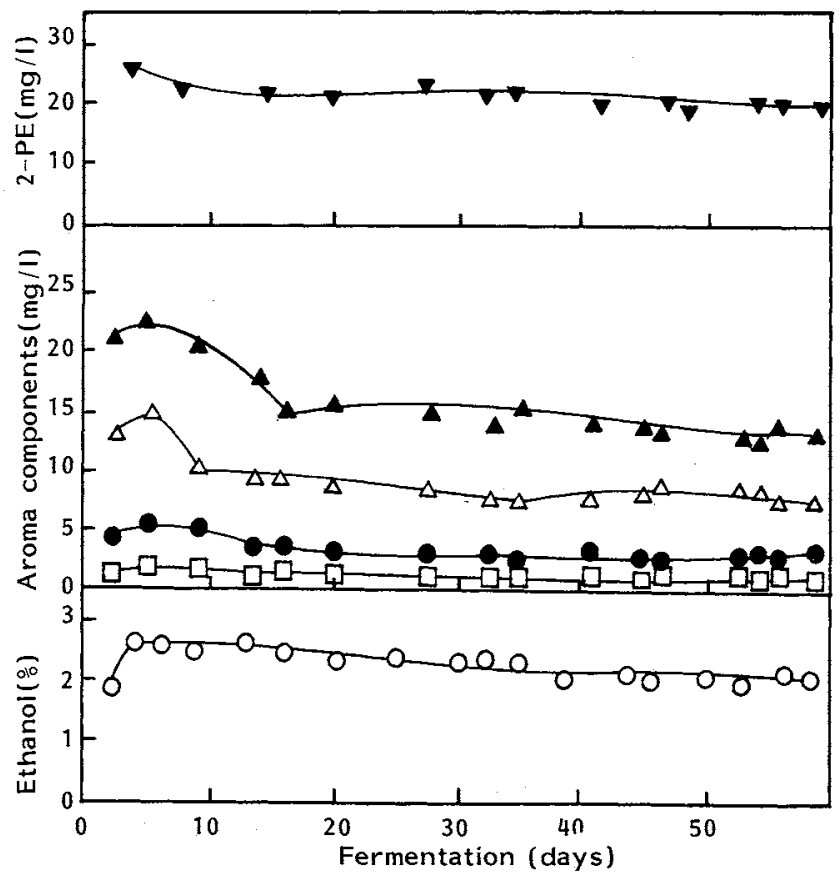

Fig. 4. Course of Ethanol and Aroma Component Production by Reactor $I$ in Continuous Fermentation Using a Ceramic Carrier.

The flow rate is $10 \mathrm{ml} / \mathrm{hr}$; retention time, 4 days; reactor temperature, $30^{\circ} \mathrm{C}$. $\bigcirc$, ethanol; $\square$, ethyl acetate; $n$-propyl alcohol; $\triangle$, iso-butyl alcohol; $\boldsymbol{A}$, iso-amyl alcohol; $\boldsymbol{\nabla}, 2-\mathrm{PE}$.

sauce yeasts, Zygo. rouxii and $C$. versatilis, which were immobilized in the ceramic carrier, are shown in Fig. 3. Obviously, the ceramics used in this experiment is filamentous in a structure $3-5 \mu \mathrm{m}$ in width. Yeasts were adsorbed and spread throughout the ceramic carrier.

\section{Continuous fermentation by bioreactors}

For cell immobilization, yeast cells $(6.5 \times$ $10^{10}$ ) were immobilized in the ceramic carrier $\left(2.2 \times 10^{8}\right.$ cells $\left./ \mathrm{cm}^{3}\right)$. After 5 days of fermentation, immobilized cells on ceramic carrier was $2.2 \times 10^{8}$ cells $/ \mathrm{cm}^{3}$ and free cells in reaction medium of bioreactors was $5 \times 10^{6}$ cells/ $\mathrm{cm}^{3}$. So, this bioreactor system is thought to be a prolific immobilized system.

\section{Reactor I}

Zygo, rouxii was immobilized in reactor $\mathrm{I}$. The course of concentrations of ethanol, 2-PE, and major aroma components of soy sauce in reactor I are presented in Fig. 4.

Reactor I contained about $2.5 \%$ ethanol and $20 \mathrm{mg} / 1$ 2-PE on the first day. This was very fast compared to 4 days using free cells. The other aroma components reached about $15 \mathrm{mg} / 1$ of iso-amyl alcohol, $10 \mathrm{mg} / 1$ of isobutyl alcohol, $5 \mathrm{mg} / \mathrm{l}$ of $n$-propyl alcohol, and $2 \mathrm{mg} / \mathrm{l}$ of ethyl acetate.

\section{Reactor II}

The course of concentrations of aroma components in reactor $\mathrm{II}$, containing immobilized C. versatilis, is presented in Fig. 5. As can be seen in Fig. 5, about $2.5 \%$ ethanol was produced in reactor I while that in reactor II remain unchanged. In addition, 4-EG was produced at a rate of $2 \mathrm{mg} / 1$. More than $15 \mathrm{mg} / 1$ of iso amyl alcohol, $10 \mathrm{mg} / \mathrm{l}$ of isobutyl alcohol, and $5 \mathrm{mg} / 1$ of $n$-propyl alcohol were produced steadily. So also with ethyl acetate at $2 \mathrm{mg} / \mathrm{l}$. 


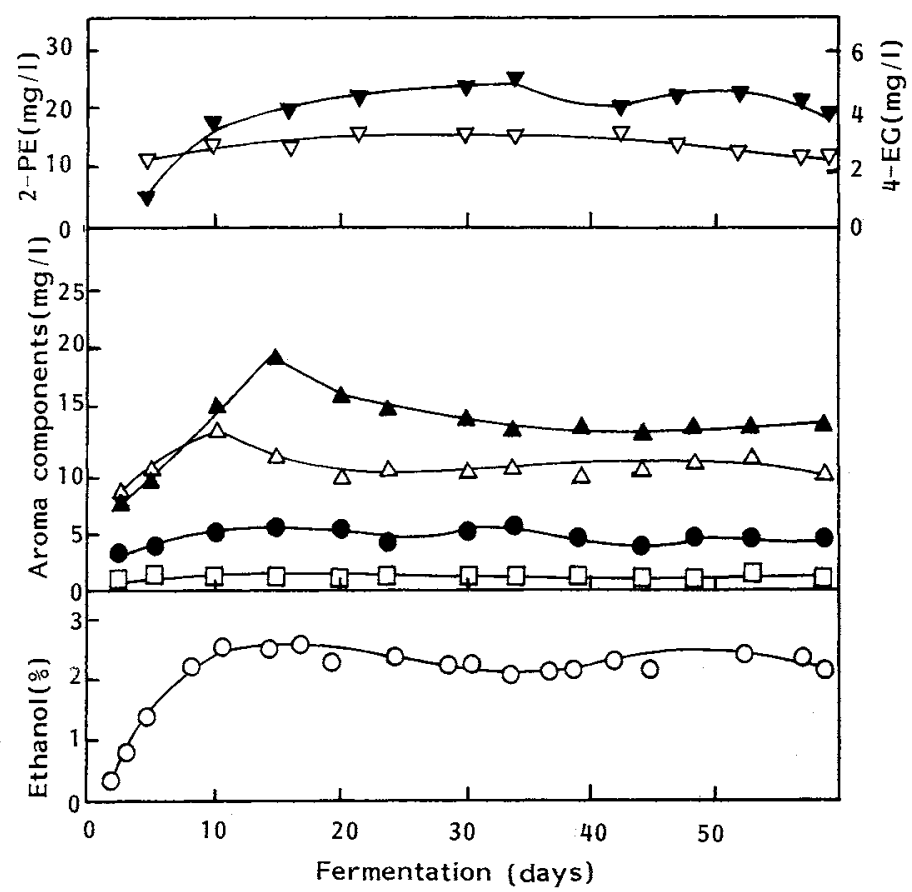

Fig. 5. Course of Ethanol and Aroma Component Production by Reactor II in Continuous Fermentation Using a Ceramic Carrier.

The flow rate, retention time, and reaction temperature were the same as in reactor $\mathrm{I} .0$, ethanol; $\square$, ethyl acetate; $\boldsymbol{D}$-propyl alcohol; $\Delta$, iso-butyl alcohol; $\boldsymbol{\Delta}$, iso-amyl alcohol; $\boldsymbol{\nabla}, 2$-PE; $\nabla, 4$-EG.

Table I. General Characteristics of Soy Sauce Produced by Conventional AND IMMOBILIZED METHODS

\begin{tabular}{llcccccc}
\hline Characteristics & & $\mathrm{pH}$ & Total acidity & $\begin{array}{c}\text { Total N } \\
(\%)\end{array}$ & $\begin{array}{c}\text { Formol N } \\
(\%)\end{array}$ & $\begin{array}{c}\mathrm{NaCl} \\
(\%)\end{array}$ & $\begin{array}{c}\text { Reducing sugar } \\
(\%)\end{array}$ \\
\hline \multirow{2}{*}{ Conventional method } & & & & & & \\
& $(\mathrm{B})^{*}$ & 4.84 & 2.80 & 1.58 & 1.18 & 15.54 & 0.91 \\
& $(\mathrm{C})^{*}$ & 4.92 & 2.49 & 1.61 & 1.24 & 14.28 & 0.77 \\
\multirow{2}{*}{ Immobilized method } & $(\mathrm{A})^{* *}$ & 4.89 & 2.40 & 1.54 & 1.14 & 16.25 & 0.84 \\
\end{tabular}

* Commercial products.

** Our data.

\section{Comparison of aroma components}

Products from continuous fermentation in reactors I and II were compared with commercial soy sauce with regard to the major constituents and aroma components. The results are shown in Tables I and II. As can be seen in Table $I$, there is not much difference in the major constituents between our product and the commercial products. But Table II indicates that concentration of $4-E G$, the unique aroma component of soy sauce, is lower in Osaki's data than any other product, while concentrations of iso-amyl alcohol and iso-butyl alcohol of his data are too high compared with other products. However, in contrast to Osaki's data, ours show better result with regard to aroma components compared with commercial soy sauce. Sensory evaluations conducted gave a high commendation of our product.

From the above-mentioned facts, our process with soy sauce yeasts, Zygo. rouxii and $C$. 
Table II. Comparison of Aroma Components of Soy Sauce Produced by Conventional AND IMMOBILIZED METHODS

\begin{tabular}{|c|c|c|c|c|c|c|c|c|c|c|}
\hline Aroma components ${ }^{a}$ & I & II & III & IV & $\mathrm{V}$ & VI & VII & VIII & IX & $X$ \\
\hline Conventional method $(\mathrm{A})^{*}$ & 2.29 & 5.3 & 1.4 & 17.7 & 25.0 & 5.0 & 13.3 & 4.9 & 3.5 & 6.5 \\
\hline$(\mathrm{B})^{*}$ & 2.32 & 4.5 & 1.4 & 16.0 & 14.4 & 8.2 & 2.1 & 7.3 & 3.0 & 14.7 \\
\hline$(C)^{*}$ & 2.49 & 4.6 & 1.6 & 18.4 & 12.6 & 4.0 & 10.1 & 9.4 & 3.4 & 4.5 \\
\hline Immobilized method $(\mathrm{A})^{* *}$ & 2.21 & 16.0 & 2.4 & 14.7 & 10.5 & 4.9 & 1.2 & 1.5 & 4.3 & 3.2 \\
\hline$(\mathrm{B})^{* * *}$ & 2.40 & 21.6 & 0.5 & 63.2 & 35.3 & - & - & 8.3 & 5.2 & 4.6 \\
\hline
\end{tabular}

a I, ethanol (\%); II, 2-PE (mg/t); III, 4-EG; IV, iso-amyl alcohol; V, iso-butyl alcohol; VI, $n$-propyl alcohol; VII, ethyl acetate; VIII, ethyl lactate; IX, furfuralcohol; X, n-butyl alcohol.

* Commercial products.

** Our data.

*** Data from Osaka et al.

versatilis immobilized on ceramic carrier, the first time in Japan, works effectively.

The total time required for fermentation by immobilized-cell reactors was shortened to only 8 days, which is much shorter than 6 months in the conventional process, while at the same time producing good quality of soy sauce. With this as a foundation, we would like to do the scale-up experiment in the future. Results of this investigation have already been patented, ${ }^{4)}$ and were presented during the annual meetings of Nippon Nogeikagaku Kai. ${ }^{5,6)}$

Acknowledgment. We are especially grateful to Kikkoman Corporation for supplying raw sauce.

\section{References}

1) K. Osaki, Y. Okamoto, T. Akao, S. Nagata and H. Takamatsu, J. Food Sci., 50, 1289 (1985).

2) H. Takamatsu, T. Iwase and T. Yokotsuka, Japan Patent, 11120, 428 (Oct. 28, 1982).

3) Y. Hirose, "Shoyu Shikenho," Nihon Shoyu Kenkyusho, Tokyo, 1985, pp. 2-23.

4) H. Horitsu, Japan Kokai Tokkyo Koho, 151176 (July 6, 1987).

5) H. Horitsu, K. Imai, K. Kouno and K. Kawai, Abstracts of Papers, the Agricultural Chemical Society of Japan, Kyoto, April, 1986, p. 486.

6) H. Horitsu, K. Kouno, Y. Maseda and K. Kawai, Abstracts of Papers, the Agricultural Chemical Society of Japan, Tokyo, April, 1987, p. 139. 